\title{
BEHAVIOR OF BUBBLES IN A SEMI-CYLINDRICAL GAS-SOLID FLUIDIZED BED
}

\author{
Yasuo HATATE, Desmond F. KING, Mitsunobu MIGITA \\ AND ATSUSHI IKARI \\ Department of Chemical Engineering, Kagoshima University, Kagoshima 890
}

\author{
Key Words: Fluidization, Chemical Reactor, Semicylindrical Bed, Bubble Size, Bubble Rise Velocity
}

\begin{abstract}
A semicylindrical fluidized bed of $15 \mathrm{~cm}$ diameter with a transparent flat wall was employed to observe bubbles visually. The bed was operated in a range of $\left(U_{G}-U_{m f}\right)$ from 8 to $35 \mathrm{~cm} / \mathrm{s}$, showing the bubbling and slugging regimes. No effect of particle size on bubble size was observed for different sands of 75 to $521 \mu \mathrm{m}$ in average diameter, where the different sands were compared at the same $\left(U_{G}-U_{m f}\right)$ value. The expressions for bubble growth in bubbling three-dimensional beds by Darton et al. and by Mori and Wen were found to be applicable to the semi-cylindrical fluidized bed operating in these regimes. The absolute bubble rise velocity under the present conditions was found to be well represented by the expression of Allahwala et al. developed for three-dimensional beds.
\end{abstract}

\section{Introduction}

To measure bubble size and bubble rise velocity important fundamental properties of gas fluidized beds- various methods ${ }^{8)}$ have been proposed and developed and a large amount of such data has been accumulated. With methods that employ threedimensional beds, it is difficult to obtain the movement of each bubble easily and directly by visual observation. Two-dimensional fluidized beds are suitable for direct visual observation, but the data from 2$\mathrm{D}$ beds are qualitative and of limited applicability to 3-D beds. Semi-cylindrical beds have been used to observe jets in fluidized beds and spouted beds, proving that semi-cylindrical beds are a useful tool that allow direct observation of in-bed phenomena with only minor wall interference. ${ }^{5,10,13)}$

In the present work, bubbles and/or slugs were observed using a $15 \mathrm{~cm}$ semi-cylindrical fluidized bed with a flat Pyrex glass front face. The effect of bed particles on the average size and the average rising velocity of bubbles and/or slugs was investigated at comparatively high gas velocities above the onset of slugging defined by Stewart $e t$ al. ${ }^{12)}$ The particles used covered a wide range of sizes from 75 to $521 \mu \mathrm{m}$ (Geldart's Group B). ${ }^{4}$

\section{Experimental}

Four cuts of sand were used, as shown in Table 1, and air was used as the fluidizing medium in all experiments. In Table 1 the volume to surface average

Received April 17, 1984. Correspondence concerning this article should be addressed to Y. Hatate. D. F. King is now at Chevron Research Center, 576 Standard Avenue, Richmond, California 94802 , USA. size $d_{p 32}$ determined by photography is shown as well as the usual average size of solid particles $d_{p}$ determined by a sieve analysis. ${ }^{* 1}$ Considering that the average size obtained from photography is a little larger than that from a sieve analysis due to the appreciable effect of projecting areas of particles, $d_{p}$ from the sieve analysis is taken as the average size of sand particles. $U_{m f}$ was measured at room temperature $\left(\simeq 25^{\circ} \mathrm{C}\right)$.

Experimental apparatus and procedure

A schematic diagram of the experimental apparatus is shown in Fig. 1. The fluidized bed, fabricated of steel, is semi-cylindrical with an internal diameter of $147 \mathrm{~mm}$ and a height of $1525 \mathrm{~mm}$. Three Pyrex glass windows of size $300 \times 147 \mathrm{~mm}$ and a quartz glass window of size $120 \times 147 \mathrm{~mm}$ form the flat face of the semi-cylindrical column. Through the windows, adjacent bubbles and/or slugs are visible. A perforated distributor plate was employed. As shown in Fig. 2, the distributor has 88 holes of $1 \mathrm{~mm}$ diameter in square pitch.

The flow rate was measured by a bank of calibrated orifice meters. To prevent the blockage of pressure taps, an extremely small flow of air was fed to $P_{1}-P_{5}$. Operation at a given condition was maintained for about 10 minutes to attain steady state. A high speed video-camera system (by Sony Co., Ltd., exposure time $=1 / 800 \mathrm{~s}, \quad 60$ frames $/ \mathrm{s}$ ) was employed to photograph the bubbles. In the measurement of bubble size, the lower ( 0 to $40 \mathrm{~cm}$ above the distributor) and the upper ( $40 \mathrm{~cm}$ to the top surface) parts of the

\footnotetext{
*1 $d_{p}=1 / \sum\left(x_{i} / d_{p i}\right)$, where $x_{i}$ is the mass fraction on sieve $i$, and $d_{p i}$ is the average diameter of particles on each sieve.
} 
Table 1. Properties of sand particles

\begin{tabular}{cccc}
\hline $\begin{array}{c}d_{p} \\
{[\mu \mathrm{m}]}\end{array}$ & $\begin{array}{c}d_{p 32} \\
{[\mu \mathrm{m}]}\end{array}$ & $\begin{array}{c}U_{m f} \\
{[\mathrm{~cm} / \mathrm{s}]}\end{array}$ & $\begin{array}{c}\varepsilon_{m f} \\
{[-]}\end{array}$ \\
\hline 75.2 & 119 & 0.890 & 0.513 \\
189 & 334 & 3.30 & 0.496 \\
281 & 461 & 10.2 & 0.479 \\
521 & 925 & 33.2 & 0.476 \\
\hline
\end{tabular}

Density $=2.51 \mathrm{~g} / \mathrm{cm}^{3}$.

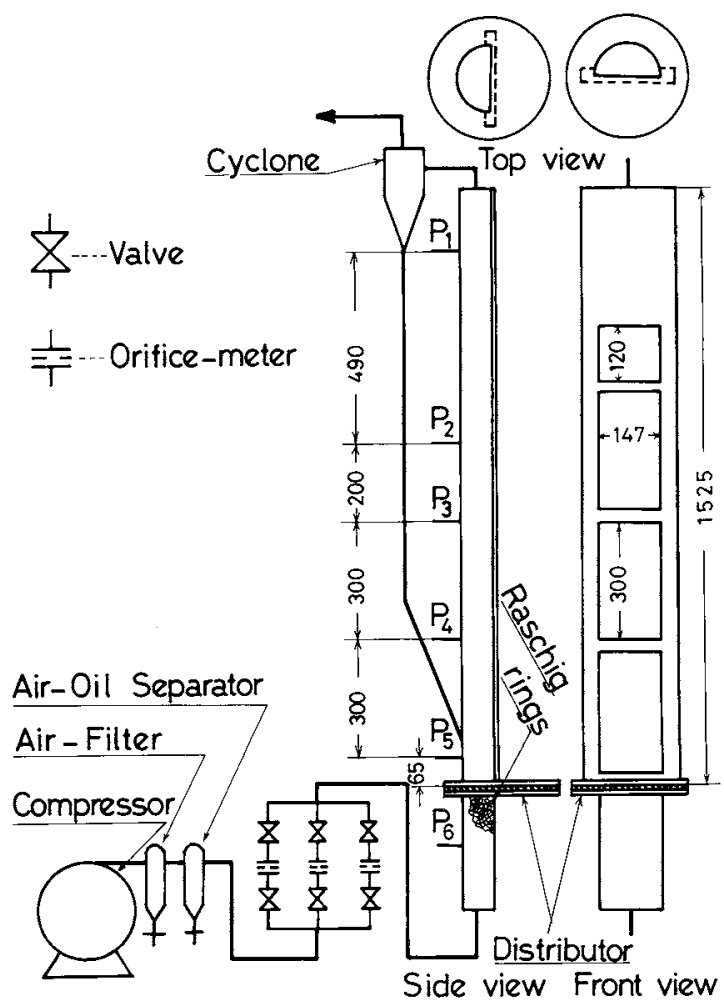

Fig. 1. Experimental apparatus.

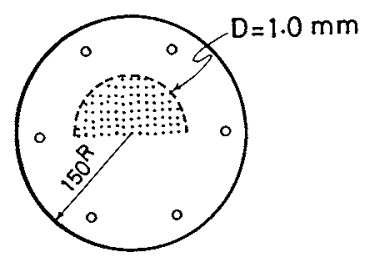

\section{8 holes}

Fig. 2. Distributor (iron plate of $6.0 \mathrm{~mm}$ thickness).

bed were separately photographed, and in order to measure the bubble rise velocity all observation windows were photographed simultaneously and recorded on a VTR. Representative photos of bubbles are shown in Fig. 3.

The VTR pictures were analyzed to determine the average size and the average rising velocity of bubbles.

To determine the average equivalent bubble size, the longitudinal and lateral lengths were measured for each well-formed bubble with almost symmetric

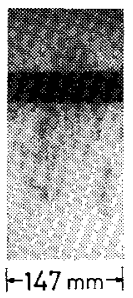

(a)

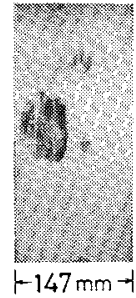

(b)

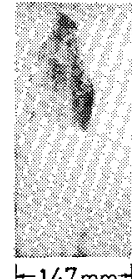

(c)

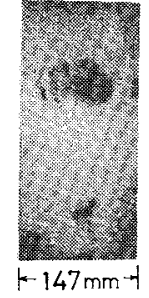

(d)
Fig. 3. Representative photos of bubbles ((a) $d_{p}=75.2 \mu \mathrm{m}$, $U_{G}-U_{m f}=25 \mathrm{~cm} / \mathrm{s}$, (b) $d_{p}=189 \mu \mathrm{m}, U_{G}-U_{m f}=12 \mathrm{~cm} / \mathrm{s}$, (c) $d_{p}=189 \mu \mathrm{m}, U_{G}-U_{m f}=25 \mathrm{~cm} / \mathrm{s}$, (d) $d_{p}=521 \mu \mathrm{m}, U_{G}-U_{m f}=$ $12 \mathrm{~cm} / \mathrm{s})$.

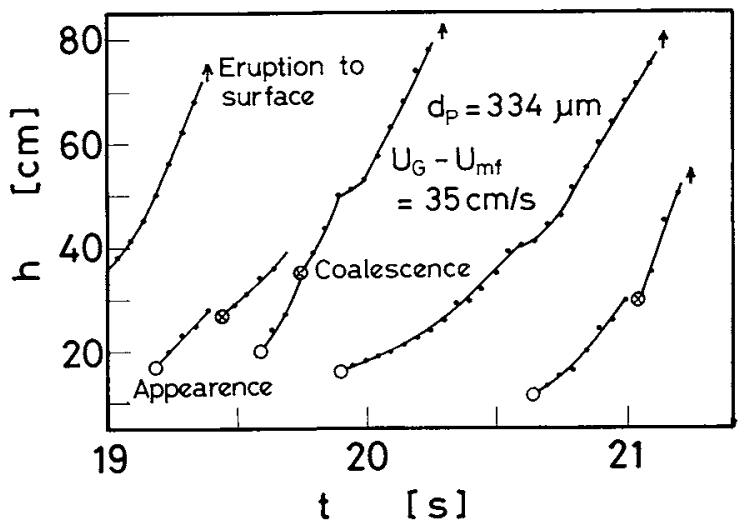

Fig. 4. Behavior of bubbles.

shape of semi-spherical cap or semi-bullet on the front glass plate. It was not so difficult to select VTR pictures of such bubbles because the inside of a bubble on the glass plate could be easily observed through the plate. For the average rising velocity, the bubble height above the distributor and the elapsed time were read from the TV monitor. An example of the relationship observed between bubble height and elapsed time is shown in Fig. 4.

Usually, 100 to 200 bubbles were chosen for inspection. In a few runs about 400 bubbles were inspected for detailed distributions of both bubble size and bubble rise velocity.

\section{Determination of Average Size and Average Rising Velocity of Bubbles}

Average bubble size Let $L$ and $D$, respectively, be the longitudinal and lateral lengths of a bubble.

From the observation of more than 200 bubbles for the $281 \mu \mathrm{m}$ sand particles at $U_{G}-U_{m f}=12 \mathrm{~cm} / \mathrm{s}$, bubble shape has been found to depend on $L / D$ as below.

1) A typical spherical cap shape is found for $L / D \leq 0.5$, so the upper part of a hemisphere is a good approximation to describe the shape.

2) A bullet shape with a comparatively sharp nose is found for $L / D>1.0$. The smoothed curve portion from the nose to the lower cylindrical part is approximately described with a parabola. The vertical length of the smoothed curve portion can be approxi- 


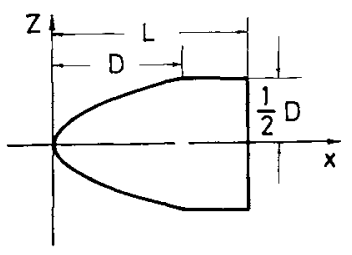

$$
\begin{aligned}
& Z= \pm \frac{1}{2} \sqrt{D x} \text { for } x \leq D \\
& Z= \pm \frac{1}{2} D \text { for } D<x \leq L
\end{aligned}
$$

Fig. 5. Bubble shape model for $L / D>1.0$.

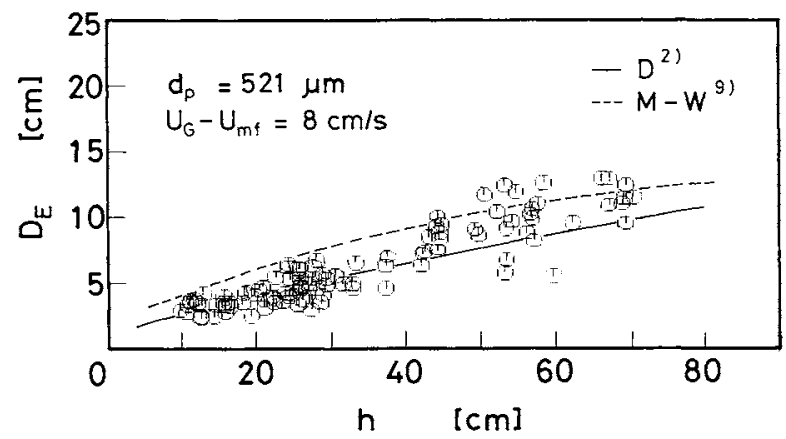

Fig. 6. Relation between $D_{E}$ and $h$.

mated by $D$, which is the diameter of the cylindrical part as shown in Fig. 5.

3) An intermediate shape between the abovementioned two types is found for $0.5<L / D \leq 1.0$.

Therefore, depending on $L / D$, the equivalent diameter $D_{E}$ can be calculated from the following equations (see Appendix).

$$
\begin{gathered}
D_{E}=D\left[(L / D)\left((L / D)^{2}+3 / 4\right)\right]^{1 / 3} \\
\text { for } L / D \leq 0.5 \\
D_{E}=(1 / 2) D_{\max }\left[4 f^{3}+2\left(2\left(L / D_{\max }\right)-f\right)\right. \\
\left.\times\left(1+f+f^{2}\right)\right]^{1 / 2} \\
\text { for } 0.5<L / D \leq 1.0 \\
D_{E}=(1 / 2) D[6+12((L / D)-1)]^{1 / 3} \\
\text { for } L / D>1.0
\end{gathered}
$$

where

$$
\begin{gathered}
D_{\max }=D[((2-f) / f)-(2(1-f) / f)(L / D)], \\
f=1.455-0.91(L / D)
\end{gathered}
$$

A representative example of bubble growth in terms of the equivalent diameters is shown in Fig. 6.

The volume average diameter*2 has been adopted for the average bubble size at given bed heights of $15 \pm 5 \mathrm{~cm}, 25 \pm 5 \mathrm{~cm}, 40 \pm 10 \mathrm{~cm}$ and $60 \pm 10 \mathrm{~cm}$ from the distributor.

\footnotetext{
${ }^{* 2} \bar{D}_{E}=\left(\sum D_{E, i}^{3} / N\right)^{1 / 3}$, where $D_{E, i}$ is the equivalent diameter of $i$ bubble $(i=1,2, \cdots, N)$ in a given bed height range.
}

Average rising velocity Such figures as Fig. 4 were used to determine the bubble rise velocities at 20,40 and $60 \mathrm{~cm}$ above the distributor. The arithmetic mean of these values at a given height is adopted as the average rise velocity. Due to the quite broad distribution of bubble rise velocities, the standard deviation was calculated to indicate the degree of variation.

\section{Results and Discussion}

For visual observation through the front glass face of the semi-cylindrical bed, bubbles greater than $20 \mathrm{~mm}$ in size are desirable. Smaller bubbles tend to move toward the interior of the bed and disappear from view. Hence, the semi-cylindrical bed seems to be suitable for observation at comparatively high gas velocities.

The experimental conditions are summarized in Table 2. Gas velocities equal to or greater than $8 \mathrm{~cm} / \mathrm{s}$ were chosen-i.e. the calculated gas velocity from Stewart's criterion (equation (4)) for the onset of slugging. ${ }^{12)}$

$$
U_{G}-U_{m f} \geq 0.2 \times 0.35 \sqrt{g D_{T}}
$$

Almost all combinations of the operating parameters listed in Table 2 were investigated to measure both bubble size and rising velocity.

Published data on both longitudinal and lateral lengths of bubble in 3-D fluidized beds seem to be rare for the experimental conditions of this work. Hence, for comparison of the data from this work with the published data, ${ }^{6}$ the stable slug length $L_{S}$ is selected and plotted against $\left(U_{G}-U_{m f}\right) / 0.35 \sqrt{g D_{T}}$ as shown in Fig. 7. Here, plotting is made only for slugs at the conditions of $\left(U_{G}-U_{m f}\right) \leq 12 \mathrm{~cm} / \mathrm{s}$ because $H$ is not so high as to make fully developed slugs at $\left(U_{G}-U_{m f}\right) \geq 25 \mathrm{~cm} / \mathrm{s}$. A stable slug is defined as a bubble of $D_{E}>0.9 D_{T}{ }^{7)}$ The solid line in the figure shows the calculated slug length from the following equation $^{6)}$ based on an assumption that the vertical distance between two successive stable slugs is $2 D_{T}$.

$$
\begin{aligned}
\left(L_{S} / D_{T}\right) & -0.495\left(L_{S} / D_{T}\right)^{1 / 2} \\
& \times\left(1-\left(U_{G}-U_{m f}\right) /\left(0.35 \sqrt{g D_{T}}\right)\right)+0.061 \\
- & 1.939\left(U_{G}-U_{m f}\right) /\left(0.35 \sqrt{g D_{T}}\right)=0
\end{aligned}
$$

Good agreement with the published data shows that the measured results from the semi-cylindrical bed could be applied to the 3-D fluidized bed.

\subsection{Average bubble size}

$d_{p}$ The effect of the sand size on the bubble size is shown in Fig. 8, where the change of bubble size with height is given for all four sands at $\left(U_{G}-U_{m f}\right)$ of $12 \mathrm{~cm} / \mathrm{s}$. Within the range of experimental error, the sizes of bubble at a given height are independent of particle size. The solid and dotted lines in the figure 
Table 2. Experimental conditions

Particle: Sands shown in Table 1

Static bed height: $70 \mathrm{~cm}$

$U_{G}-U_{m f}: 8,12,25$ and $35 \mathrm{~cm} / \mathrm{s}$

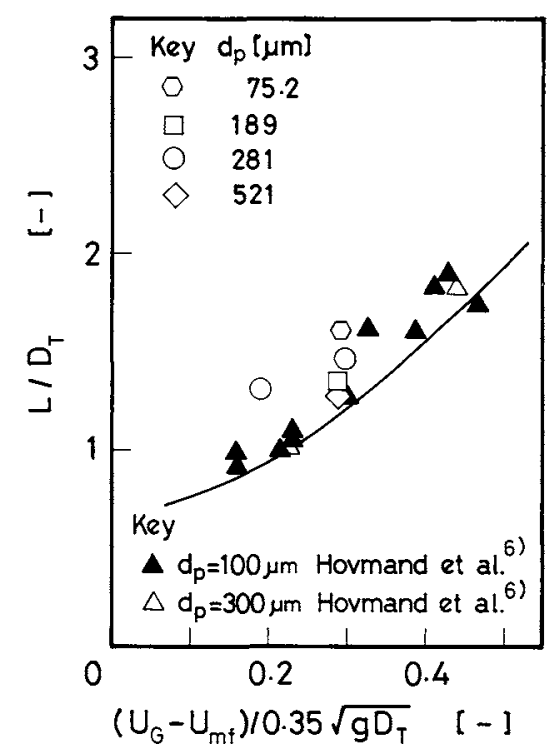

Fig. 7. Comparison of slug length with published data 3-D beds.

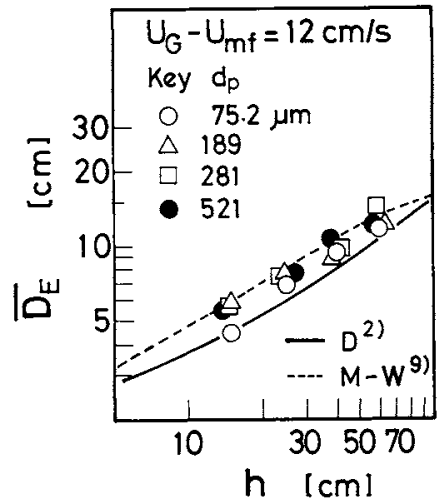

Fig. 8. Effect of particle size on $\bar{D}_{E}$ vs. $h$ relation.

show the calculated relations between $D_{E}$ and $h$ from Eq. (6) by Darton et al. ${ }^{2 y}$ and Eq. (7) by Mori and Wen, ${ }^{9}$ respectively.

$$
\begin{aligned}
& D_{E}=0.54\left(U_{G}-U_{m f}\right)^{0.4}(h+4 \sqrt{A / n})^{0.8} / g^{0.2} \\
& D_{E}=D_{B M}-\left(D_{B M}-D_{B o}\right) \exp \left(-0.3 h / D_{T}\right)
\end{aligned}
$$

where

$$
\begin{aligned}
& D_{B O}=0.347\left(\left(U_{G}-U_{m f}\right) A / n\right)^{0.4} \\
& D_{B M}=0.652\left(\left(U_{G}-U_{m f}\right) A\right)^{0.4}
\end{aligned}
$$

It is evident from Fig. 8 that both of the above equations predict the $D_{E}$ data under the present operating conditions.

$U_{G}-U_{m f}$ In Fig. 9, the observed average bubble sizes are plotted against the bed heights in the range of

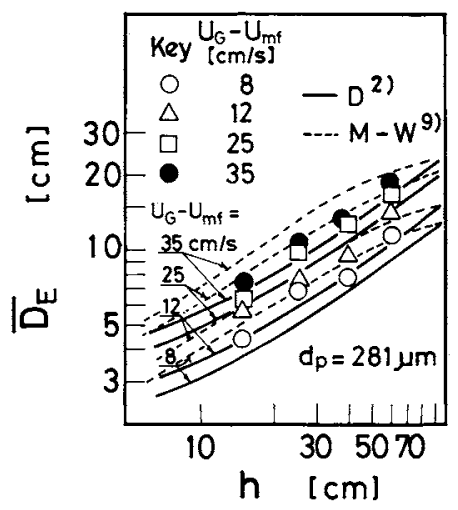

Fig. 9. Effect of $\left(U_{G}-U_{m f}\right)$ on $\bar{D}_{E}$ vs. $h$ relation.

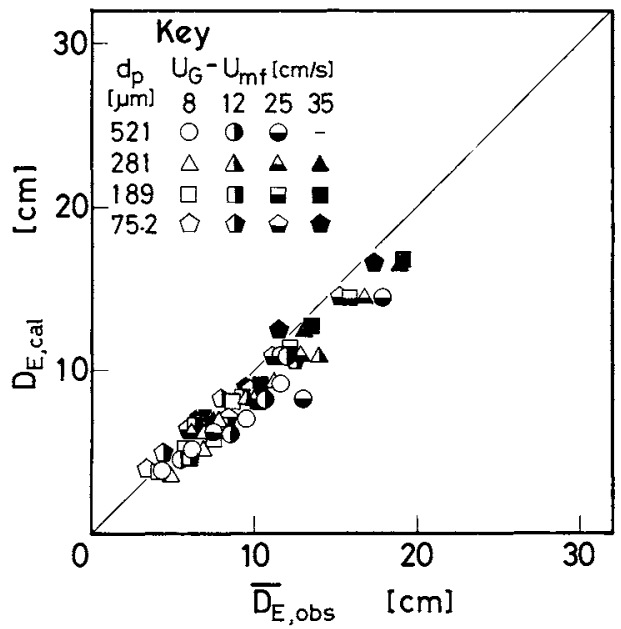

Fig. 10. Comparison of observed $\bar{D}_{E}$ with calculated $D_{E}$ from Eq. (6).

$\left(U_{G}-U_{m f}\right)$ from 8 to $35 \mathrm{~cm} / \mathrm{s}$ using the sand of $d_{p}=$ $281 \mu \mathrm{m}$. Both the solid and dotted lines calculated from Eqs. (6) and (7), respectively, show comparatively good agreement with the experimental data.

Comparisons between the observed bubble sizes and those calculated from the equation of Darton et al. are shown in Fig. 10 to examine the applicability of Eq. (6) over the whole range of operating parameters. The applicability of the Mori-Wen equation to the present $D_{E}$ data is examined in Fig. 11. Although a little underestimation from Eq. (6) and a little overestimation from Eq. (7) are observed at heigher bed heights, agreement between observed and calculated values in both cases is still good.

\subsection{Average rising velocity}

$d_{p}$ The effect of particle size on $U_{B}$ is shown in Fig. $\overline{\mathbf{1 2}}$, where the change of average rising velocity with height is given for four sands at $U_{G}-U_{m f}=12 \mathrm{~cm} / \mathrm{s}$. In spite of the large scattering of $U_{B}$, the rising velocities seem independent of particle size. Only the sand of $521 \mu \mathrm{m}$ shows smaller rising velocities at lower bed heights than the other three sands. The solid line in the figure, which is calculated from the following correlation by Allahwala and Potter, ${ }^{1)}$ shows com- 


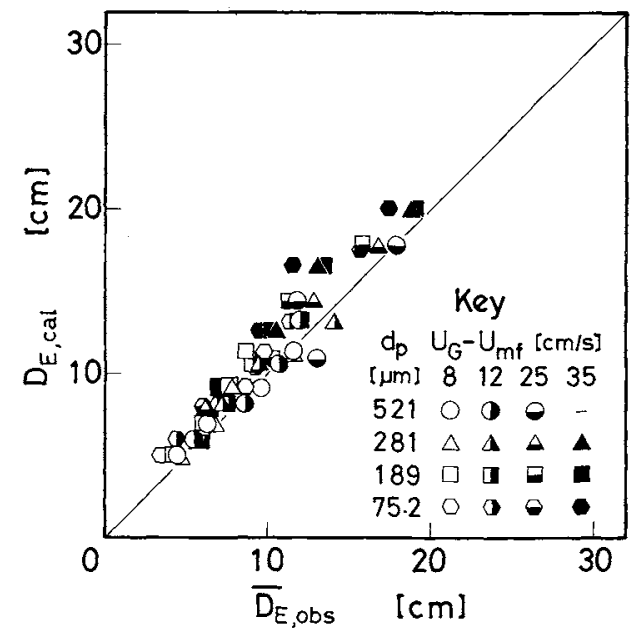

Fig. 11. Comparison of observed $\bar{D}_{E}$ with calculated $D_{E}$ from Eq. (7).

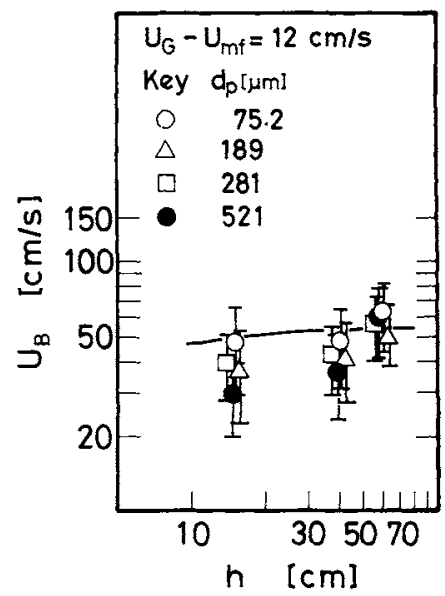

Fig. 12. Effect of particle size on $U_{B}$ vs. $h$ relation.

paratively good agreement with the experimental data.

$$
\begin{aligned}
U_{B}= & 0.35 \sqrt{g D_{T}} \tanh ^{1 / 1.8}\left\{3.6\left(\sqrt{D_{E} / D_{T}}\right)^{1.8}\right\} \\
& +U_{G}-U_{m f}
\end{aligned}
$$

Equation (8) is applicable to the full range of flow regimes, involving the bubbling regime ${ }^{3)}$ and the slugging regime.

$U_{G}-U_{m f}$ In Fig. 13, the observed average rising velocities are plotted against the bed heights for a range of $\left(U_{G}-U_{m f}\right)$ from 8 to $35 \mathrm{~cm} / \mathrm{s}$ using the sand of $d_{p}=189 \mu \mathrm{m}$. The solid lines calculated from Eq. (8) show comparatively good agreement with the experimental data. At lower bed heights the observed rising velocities are smaller than those calculated. The observed rising velocities at bed heights above $40 \mathrm{~cm}$ show comparatively good agreement with the calculated values.

\section{Conclusions}

Through the windows of the front face of a semi-

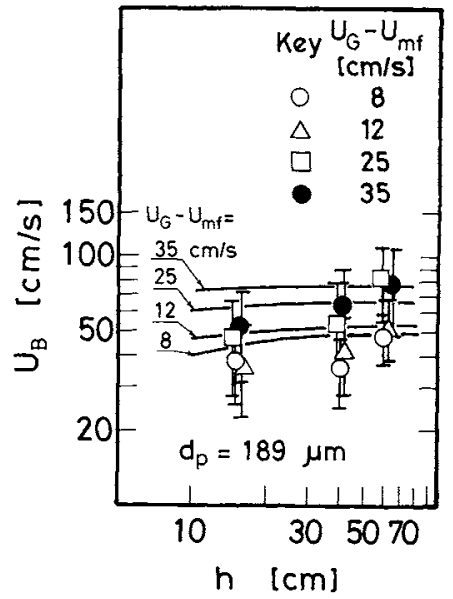

Fig. 13. Effect of $\left(U_{G}-U_{m f}\right)$ on $U_{B}$ vs. $h$ relation.

cylindrical column, bubbles and/or slugs were observed visually in order to measure bubble sizes and rising velocities. Within the present experimental conditions, the following aspects were found.

1) With the semi-cylindrical column the behavior of bubbles was observed as easily as in a twodimensional fluidized bed. The measured values of stable slugs were found to be in agreement with published data ${ }^{6}$ for three-dimensional fluidized beds, indicating that the results from semi-cylindrical fluidized bed experiments are pertinent to the design and scale-up of 3-D beds.

2) The bubbling to slugging regimes were investigated in this work with $\left(U_{G}-U_{m f}\right)$ ranging from 8 to $35 \mathrm{~cm} / \mathrm{s}$. The obtained $D_{E}$ data showed comparatively good agreement with those from the Mori-Wen equation. ${ }^{9)}$ An expression derived by Darton et al. ${ }^{27}$ to predict bubble sizes in truly bubbling fluidized beds was found to be also applicable in a bed where the transition from bubbling to slugging predominates.

3) No discontinuity or qualitative change in bubble behavior is detected with change of particle size of sands from $d_{p}=75$ to $521 \mu \mathrm{m}$, covering Geldart's group B.

\section{Appendix}

A bubble of $0.5 \leq L / D<1.0$, which is described as one bounded by the thin line in Fig. A-1, is assumed to be a portion of the fictitious bubble shown by the heavy dotted line. That fictitious bubble has $D_{\max }$ as the longitudinal length as well as the lateral

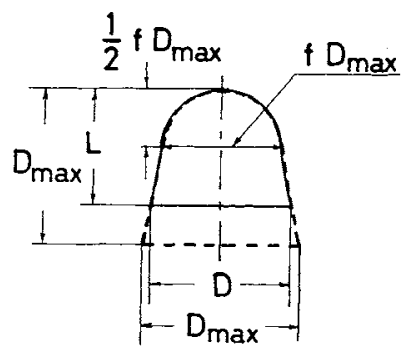

Fig. A-1. A model for bubble shape of $0.5<L / D \leq 1.0$. 
length (=maximum diameter). Further detailed assumptions are as follows: 1. The nose portion of the bubble is described as a hemisphere of $f D_{\max }$ in diameter. 2. The side portion of the bubble below the hemisphere is described as a conical trapezoid, as shown in Fig. A-1. 3. $L$ and $D$ represent the vertical length and the bubble diameter at the bottom of the bubble, respectively.

Equation (2) can be easily derived with the above assumption. To satisfy the compatibility of both shape and calculated volume with increasing $L / D$, the shape factor $f$ must be 1 at $L / D=0.5$ and 0.545 at $L / D=1.0$. Assuming linearity, $f=1.455-0.91(L / D)$. Bubbles become more spherical with increasing $f$, and sharper with decreasing $f$.

\section{Acknowledgment}

The authors are thankful to Drs. R. Yamazaki, S. Moro-oka and $\mathrm{S}$. Mori for their useful suggestions and discussion regarding the present study.

\begin{tabular}{|c|c|c|c|}
\hline \multicolumn{4}{|c|}{ Nomenclature } \\
\hline$A$ & & cross sectional area of bed & {$\left[\mathrm{cm}^{2}\right]$} \\
\hline$D$ & & $\begin{array}{l}\text { lateral length }(=\text { maximum diameter }) \text { of } \\
\text { bubble }\end{array}$ & [cm] \\
\hline$D_{B 0}$ & $=$ & initial bubble diameter at distributor & [cm] \\
\hline$D_{B M}$ & & $\begin{array}{l}\text { maximum bubble diameter due to total } \\
\text { coalescence of bubbles }\end{array}$ & [cm] \\
\hline$D_{E}$ & $=$ & equivalent diameter of bubble & {$[\mathrm{cm}]$} \\
\hline $\bar{D}_{E}$ & $=$ & volume average diameter of bubbles & {$[\mathrm{cm}]$} \\
\hline$D_{\max }$ & $=$ & $\begin{array}{l}\text { maximum diameter of fictitious bubble defin } \\
\text { in Fig. A-1 }\end{array}$ & {$[\mathrm{cm}]$} \\
\hline$D_{T}$ & $=$ & bed diameter & {$[\mathrm{cm}]$} \\
\hline$d_{p}$ & $=$ & $\begin{array}{l}\text { average diameter of solid particles by sieve } \\
\text { analysis }\end{array}$ & {$[\mu \mathrm{m}]$} \\
\hline$d_{p 32}$ & $=$ & $\begin{array}{l}\text { volume to surface average diameter of partic } \\
\text { by photographic analysis }\end{array}$ & cles \\
\hline$f$ & $=$ & shape factor defined in Appendix & {$[-]$} \\
\hline$g$ & $=$ & gravitational acceleration & $\left.\mathrm{cm} / \mathrm{s}^{2}\right]$ \\
\hline$H$ & $=$ & total height of bed & {$[\mathrm{cm}]$} \\
\hline
\end{tabular}

$h \quad=$ bed height above distributor $\quad$ [cm]

$L=$ longitudinal length of bubble [cm]

$L_{\mathrm{S}} \quad=$ stable slug length $\quad[\mathrm{cm}]$

$n \quad=$ number of orifices in distributor plate $\quad[-]$

$U_{B} \quad=$ bubble rise velocity $\quad[\mathrm{cm} / \mathrm{s}]$

$U_{G} \quad=$ superficial gas velocity $\quad[\mathrm{cm} / \mathrm{s}]$

$U_{m f} \quad=$ minimum fluidization velocity $\quad[\mathrm{cm} / \mathrm{s}]$

$\varepsilon_{m f} \quad=$ bed voidage at minimum fluidization $\quad[-]$

\section{Literature Cited}

1) Allahwala, S. A. and O. E. Potter: Ind. Eng. Chem. Fund., 18, 112 (1979).

2) Darton, R. C., R. D. La Nauze, J. F. Davidson and D. Harrison: Trans. Instn. Chem. Engrs., 55, 274 (1974).

3) Davidson, J. F. and D. Harrison: "Fluidized Particles," Cambridge University Press (1963).

4) Geldart, D.: Powder Technology, 7, 285 (1973).

5) Horio, M., M. Hoshiba and A. Nonaka: Preprint of the 17th Autumn Meeting of The Soc. of Chem. Engrs., Japan, DS216, Oct., 1983.

6) Hovmand, S. and J. F. Davidson: Trans. Instn. Chem. Engrs., 46, T190 (1968).

7) Hovmand, S. and J. F. Davidson: "Fluidization," Chapter 5, ed. by J. F. Davidson and D. Harrison, Academic Press, New York (1971).

8) Ishida, M.: Kagaku Kōgaku, 43, 208 (1979).

9) Mori, S. and C. Y. Wen: AIChE J., 21, 109 (1975).

10) Nishizaki, H. and K. Yoshida: Preprint of the 16th Autumn Meeting of the Soc. of Chem. Engrs., Japan, E204, Oct., 1982.

11) Rowe, P. N.: "Fluidization," Chapter 4, ed. by J. F. Davidson and D. Harrison, Academic Press, New York (1971).

12) Stewart, P. S. B. and J. F. Davidson: Powder Tech., 1, $6 \mathrm{I}$ (1967).

13) Whiting, K. J. and D. Geldart: Chem. Eng. Sci., 35, 1499 (1980). 